\title{
A novel forest state assessment methodology to support conservation and forest management planning
}

\author{
T. Standovár ${ }^{1,5}$, F. Szmorad 1 , B. Kovács ${ }^{1,2}$, K. Kelemen ${ }^{1}$, M. Plattner ${ }^{3}$, T. Roth ${ }^{3}$
}

and Zs. Pataki ${ }^{4}$

\author{
${ }^{1}$ Department of Plant Systematics, Ecology and Theoretical Biology, Institute of Biology, L. Eötvös University, \\ Pázmány P. sétány 1/c H-1117 Budapest, Hungary \\ 2 MTA Centre for Ecological Research, Institute of Ecology and Botany, Alkotmány u. 2-4, H-2163 Vácrátót, Hungary \\ ${ }^{3}$ Hintermann und Weber AG, Austrasse 2a, 4153 Reinach, Switzerland \\ ${ }^{4}$ Tájinformatika GP, Vác, Hungary \\ ${ }^{5}$ Corresponding author.E-mail: standy@caesar.elte.hu
}

Keywords: Android data collection app, Forest naturalness, Forest structure, Microhabitats, Natura 2000, PostGIS, Thematic mapping.

\begin{abstract}
A new forest state assessment methodology to complement existing conservation and forestry data has been developed. The aim is to provide tools for strategic planning including spatial distribution of conservation priorities. The method is point-based using a dense systematic sampling grid and provides more detailed information than vegetation maps or forest subcompartment descriptions, but requires less effort than forest inventories. Indicators include canopy composition and structure, deadwood, herbs, microhabitats, disturbances, shrubs and regeneration. The results can inform managers about the structural and compositional diversity of forest stands in the form of thematic maps and can provide the basis for analysis of habitat suitability for forest-dwelling organisms. A smartphone application has been developed to enable electronic data collection. PostGIS and Python scripts were used in the data flow. In this paper, we outline the development of the assessment protocol, and present the sampling design and the variables recorded. The main advantages of the survey methodology are also shown by case-studies based on data collected during the first field season in 2014. The protocol has been designed for low mountain forests in Hungary, but it can be modified to fit other forest types.
\end{abstract}

Abbreviations: CWD - Coarse Woody Debris, DBH - Diameter at Breast Height, DCD - Diameter Class Diversity, FDC ForestDataCollect App., FWD - Fine Woody Debris, NFD - National Forestry Database.

\section{Introduction}

Traditionally forests were mainly used and managed for timber production. However, social expectations regarding forests have notably changed in the last few decades. These changes are reflected in the initiatives of the pan-European FOREST EUROPE process (formerly known as Ministerial Conferences on the Protection of Forests in Europe MCPFE), as well as in the statements on the role of forests in modern societies presented in the EU Forest Action Plan (EC 2006), and the New EU Forest Strategy (EC 2013). In addition to the traditional production function (timber), the other - often conflicting - functions that forests should fulfil include protective functions (e.g., of site, drinking water basis), biodiversity and ecosystem functions, social and cultural functions (e.g., health promotion, education, recreation) and economic functions (i.e., sustainable use of forest related goods and services).

One possible way to achieve these goals is to spatially separate the different functions by designating nature reserves, protective forests (soil, landslide), recreational areas and forests serving primarily wood production. However, in most parts of the world - especially in Europe with a long history of intensive land-use - the magnitude of landscape transformation (habitat destruction, fragmentation and degradation) has exceeded the threshold of habitat loss where this approach is feasible. Even in other, less deteriorated regions, because of social and economic hindrance, there is a shortage of land available for reserve allocation, and proper reserve management is often compromised. As it was stated by Lindenmayer and Franklin (2002) '... most forest will be in off-reserve, or matrix, lands in the vast majority of forest regions and forest types. Comprehensive strategies for the conservation of forest biodiversity must include both reserves and matrix-based strategies.'

This leads to the need of wise application of both segregative (strict reserves) and integrative approaches in forest biodiversity conservation. The latter means the integration of non-commercial goals in the management of forests providing multi-purpose services (Kraus and Krumm 2013). Integration of different management goals requires strategic planning using appropriate data, a decision-making process that ensures all needs are satisfied at the landscape scale, and effectiveness monitoring that provides feedback on how well human activities (or inactivity) are suited to achieve the goals. Consequently, data are needed that describe both the 
biological and commercial status and potential of an area of interest at a sufficient spatial resolution enabling spatially explicit planning.

Most existing databases contain thematically specific information that is designed to help practitioners to achieve certain management objective (e.g., production) regardless of other objectives. The combination of such databases is hindered by the differences in spatial and temporal resolution. Traditional forest management planning required data sufficient for designing forest use that assure sustained timber supply. As a result, data collecting systems developed from the early $20^{\text {th }}$ century mainly focused on tree species composition, age and size characteristics, volume and site conditions at the management unit and/or national levels (Kangas and Maltamo 2006). Similarly, while preparing conservation management plans, conservation bodies often rely only on data relevant for conservation (e.g., distribution data on rare species and vegetation types) that are often collected in reserves. However, the integration approach requires data that serve both production and non-productive objectives on a scale that is relevant to the planning process and covers both the forest-matrix and the protected stands.

There is a wide range of potential data sources on forests internationally. While exact measurement methods and availability vary from country to country, data can be categorized as forest inventories, forest management unit assessments, vegetation maps and biotic data. Forest inventories and international forest assessment programs collect detailed compositional and structural data from small samples representing large areas and are used to monitor global and regional trends rather than providing information for local planning. There have been attempts to assess how field data acquired in national forest inventories can contribute to reporting on the status and trends in forest biodiversity in the frameworks of different international agreements. The major challenge has been that there is a large variety of definitions, protocols, sampling designs, and plot configurations used in different countries, which makes the European-scale interpretation of the country reports extremely difficult. This problem could be partly solved by developing harmonization techniques that facilitate common reporting (Chirici et al. 2011, 2012).

In some countries, detailed forest management planning is done for the whole forested area. In Hungary, these plans are based on field survey and are done once in every 10 years for each of the roughly 550000 forest subcompartments. Data collected during the planning are stored in the National Forestry Database (NFD) that contains data on site conditions, composition of tree species, prescribed and already completed forest management activities for each subcompartment. While NFD is an essential instrument of planning and inspection to implement forestry policy (Tobisch and Kottek 2013), biodiversity data are largely missing.

In addition to distribution data of threatened and/or protected species, vegetation and/or habitat maps are an important tool for conservation authorities and national parks to plan their activities. They use either phytosociological units or more general habitat types as units (Evans 2006, Molnár et al. 2007, Kent 2012). However, these forestry and vegetation/ habitat maps describe only typical values of a few - mostly compositional - variables, e.g., species composition of the tree or herb layers in subcompartments or vegetation patches, regardless of the spatial variation within individual units.

All these data sources have the advantage of large spatial coverage (e.g., entire countries), but they lack the required spatial resolution (large uniformly treated polygons) and thematic richness (e.g., biologically relevant structural data are missing).

Structural data (e.g., vertical and horizontal structure of the tree canopy, amount, size- and decay stage distribution of deadwood, type and amount of microhabitats) have been collected by different specific monitoring programs, like studies on forest naturalness (Bartha et al. 2006, Grabherr et al. 1998, McRoberts et al. 2012, Winter 2012), forest reserve programs (Parvianen et al. 2000) or specific conservation research focusing on habitat needs (e.g., deadwood, microhabitats) of certain forest specialist (Ódor and van Hees 2004, Ódor et al. 2006, Müller and Bütler 2010, Larrieu et al. 2014, Gouix et al. 2015). Similar data are collected within the framework of national monitoring programs of Natura 2000 habitats (e.g., Louette et al. 2015). The Natura 2000 network of the European Union is designed to protect the most seriously threatened habitats and species across Europe according to the Habitats Directive (issued in 1992 CD 92/43/EEC), which complemented the European Birds Directive (issued in 1979 CD 79/409/EEC, revised in 2009). The main aim of the directive is to maintain and/or restore a favourable conservation status (FCS) for selected species and habitats. The concept of FCS is not unambiguously defined and applied across Europe (e.g., Mehtala and Vuorisalo 2007, Cantarello and Newton 2008, Brambilla et al. 2011), which might cause problems while interpreting the status of natural habitats in Europe based on country level reporting (EEA 2015). However, the proportion of sampled area covered by these monitoring activities is usually small compared with the total area of semi-natural forests where integrated management planning would be beneficial, which means that for large areas we have limited knowledge about the actual state of forest habitats of community interest.

In order to be able to plan forest management and conservation actions in an integrative and efficient way, higher data quality must be achieved both in terms of thematic richness and applicability over various spatial scales. Otherwise, we are not able to set quantitative let alone qualitative goals for actions favouring forest-dwelling organisms. We need data complementing existing sources of information. New data should fulfil the requirement of serving both management and conservation aspects and need to serve as the basis for complex management action plans.

Our work has been motivated by the recognition of the lack of such comprehensive data in our country. We aimed at developing and implementing a forest state assessment methodology that both provides and integratesw the necessary supplementary information to existing forestry and vegetation data and serves as a stand-alone tool for the assessment 
of conservation status of our forest at a fine spatial scale. In this paper, we present the methodology that was developed to fulfil these goals.

\section{Methods}

\section{General criteria and sampling scheme}

The forest state assessment protocol was developed within the framework of the project "Multi-purpose assessment serving forest biodiversity conservation in the Carpathian region of Hungary". The main aim of the project is to collect data that complement available information in forestry and conservation databases and integrate all for the enhancement of conservation of these habitats. The project includes the development and implementation of forest state assessment and zoological surveys on forest-dwelling bats and birds and xylophagous insects. All work has been carried out in the Northern part of Hungary, in the Börzsöny, Mátra and Aggtelek Mountains (Figure 1).

The main goal of the forest state assessment was to collect structural and compositional data that were missing and that could be used by forest management companies and conservation agencies (national parks) for strategic as well as daily planning of forestry and conservation activities. The assessment was also planned to support the analysis of forest naturalness and to enable us to find potential hotspots of biodiversity.

To the authors' knowledge such complementary studies have not yet been published and a new, comprehensive methodology had to be designed that could be carried out in large areas in a cost effective manner. Methods to be chosen had to meet the following criteria: (1) simple and fast measurements or estimates without the need for special equipment, (2) reproducible methods to allow for many field workers, (3) data comparable to existing databases, (4) appropriate data for supporting forest management planning and conservation planning. It was also required to produce thematic maps at the scale of 1:10 000 for direct use in conservation management plans and produce traditional maps such as habitat type maps.

From the very beginning we decided to use systematic point sampling in order to achieve spatially explicit data based on which maps with several distinct thematic contents could be produced. Since many national forest inventories and other investigations use $500 \mathrm{~m}^{2}$ circular plots (Tomppo et al. 2011), this size was chosen as the main sampling area at each sampling point.

\section{Variable selection and choice of measurement methods}

Potential variables were selected from existing forest inventories (Winter et al. 2008, Kolozs 2009, Chirici et al. 2011, Tomppo et al. 2011), forest naturalness surveys (Bartha et al. 2006, Paillet et al. 2008, McRoberts et al. 2012), forest reserve programs (Hochbichler et al. 2000, Christensen et al. 2005), Natura 2000 habitat monitoring (Cantarello and Newton 2008, Hernando et al. 2010, Velázquez et al. 2010), specific conservation projects (Kirby et al. 1998, McElhinny et al. 2005, Liira and Sepp 2009) and international projects e.g., ForestBIOTA (Fischer et al. 2009). A list of variables considered for our multipurpose forest state survey was put together. The extended variable list contained over one hundred items and for a number of variables several optional definitions and measurement methods were identified.

Several stakeholders (national park experts, representatives of local state forest enterprise and state forestry authority) were involved in the selection of relevant features and in defining measurement scales that could be applied in the field. Where alternative methods were available, they were tested in the field and evaluated for reproducibility, simplicity of method and time consumption as the main criteria. An example of such a pilot study is given below in detail for canopy composition.

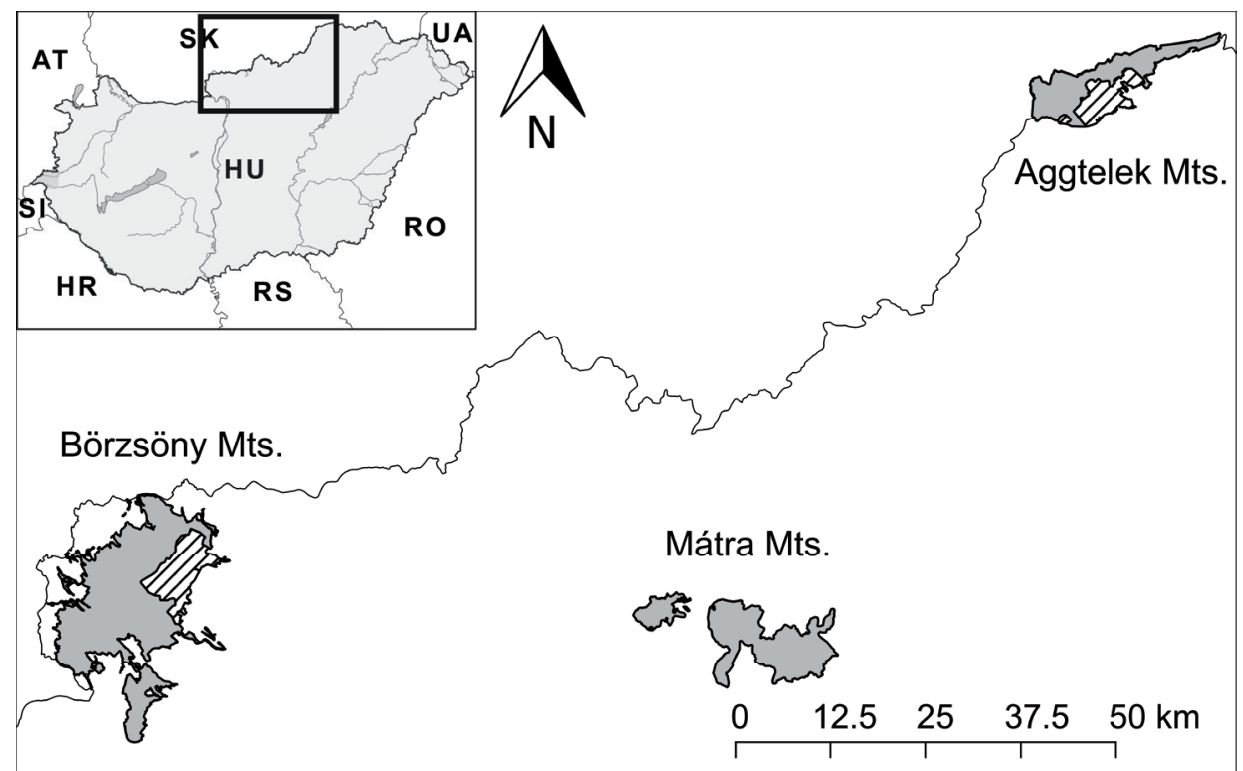

Figure 1. Project area where the implementation of the forest state survey takes place. Striped area designates mapped territory in 2014 (used for preliminary analysis in this paper), while grey areas were surveyed in 2015 and 2016. 
Existing data on canopy composition include admixing ratio, height, closure and volume of commercially important tree species. Therefore, our complementary data had to provide better estimates for species richness by being sensitive for species with low cover and for structural diversity by differentiating between age classes and vertical complexity.

To develop the method for describing canopy composition, 30 plots located in tree stands of different ages and composition have been sampled. In our novel method we planned to record canopy cover estimates for each tree species in several diameter classes. Canopy cover was estimated by using broad cover categories: $0-5 \%, 6-20 \%, 21-50 \%, 51-100 \%$. Two independent crew recorded canopy composition using two DBH category scales: Method A (five categories): 0-8 $\mathrm{cm}, 9-20 \mathrm{~cm}, 21-35 \mathrm{~cm}, 36-50 \mathrm{~cm},>50 \mathrm{~cm}$; Method B (six categories): $0-8 \mathrm{~cm}, 9-15 \mathrm{~cm}, 16-25 \mathrm{~cm}, 26-35 \mathrm{~cm}, 36-50 \mathrm{~cm}$, $>50 \mathrm{~cm}$. The extent of the $500 \mathrm{~m}^{2}$ circular plot was visually estimated. As a reference (Method C, complete survey), following estimation according to $\mathrm{A}$ and $\mathrm{B}$, the extent of the plot was measured then species name and DBH were recorded for each tree individual in the plot. Methods A and B were compared against the reference $(\mathrm{C})$ based on species admixing ratio and relative cover in diameter classes. For methods $\mathrm{A}$ and $\mathrm{B}$ admixing ratio of a species (its relative importance in the canopy) was calculated as its cover divided by total cover. Relative cover in a diameter class was derived similarly but using only data of the respective diameter class. For these calculations we used the middle values of cover categories (e.g., $75 \%$ for $51-100 \%$ ). For method C basal area (cross-sectional area of a tree species at $130 \mathrm{~cm}$ height expressed in $\mathrm{m}^{2} / \mathrm{ha}$, derived from DBH) was used for calculations. Distributions of relative cover in diameter classes were compared between
A-C and B-C using Chi-square test (test of homogeneity) plot-wise. The Chi-square test showed that method A was better than method $\mathrm{B}$ in describing diameter class distribution, while correlation between admixing ratios showed that both estimation techniques performed well $\left(\mathrm{R}^{2}=0.84, \mathrm{p}<\right.$ 0.05 ). As a conclusion, taking into account time consumption (method A was 30 seconds faster on average than method B), method A was finally chosen for the description of canopy composition and structure.

In several cases (e.g., tree related microhabitats, browsing of regeneration), new classes have been created and definitions had to be adapted. The derived list of methods including definitions have been revisited and the final variable list has been created (Table 1).

\section{The novel methodology and data collection system}

The multipurpose forest state survey is based on a systematic grid of field points. The intended average density of the grid is two points per hectare. Three different and joint grid densities were established that could be used for stands with varying structural complexity. For the most heterogeneous stands (e.g., forest reserves), a dense grid of $50 \mathrm{~m} \times 50$ $\mathrm{m}$ was laid out. By selecting every second or fourth point in more homogeneous stands, a network of sampling plots in every $70 \mathrm{~m}$ or $100 \mathrm{~m}$ was set up (Figure 2). From the latter grid sizes the denser, $70 \mathrm{~m} \times 70 \mathrm{~m}$ grid was chosen during the first year of sampling.

We use three distinct sampling units (Figure 3). At every grid point two concentric sampling plots are surveyed. Most data are collected for the $500 \mathrm{~m}^{2}$ circular plot (radius: 12.62 $\mathrm{m}$ ), while shrub and regeneration data are gathered in the $30 \mathrm{~m}^{2}$
Figure 2. Systematic sampling grid of various densities used during our survey. In the basic grid, points have a distance of $50 \mathrm{~m}$ (black filled circles). If every second point is sampled, a $70.71 \mathrm{~m}$ grid (two points per hectare) is created (grey circles). Empty circles designate the $100 \mathrm{~m}$ grid (one point per hectare). For reference, the subcompartments of the National Forestry Database are shown for a selected area in the Börzsöny Mts., Northern Hungary.
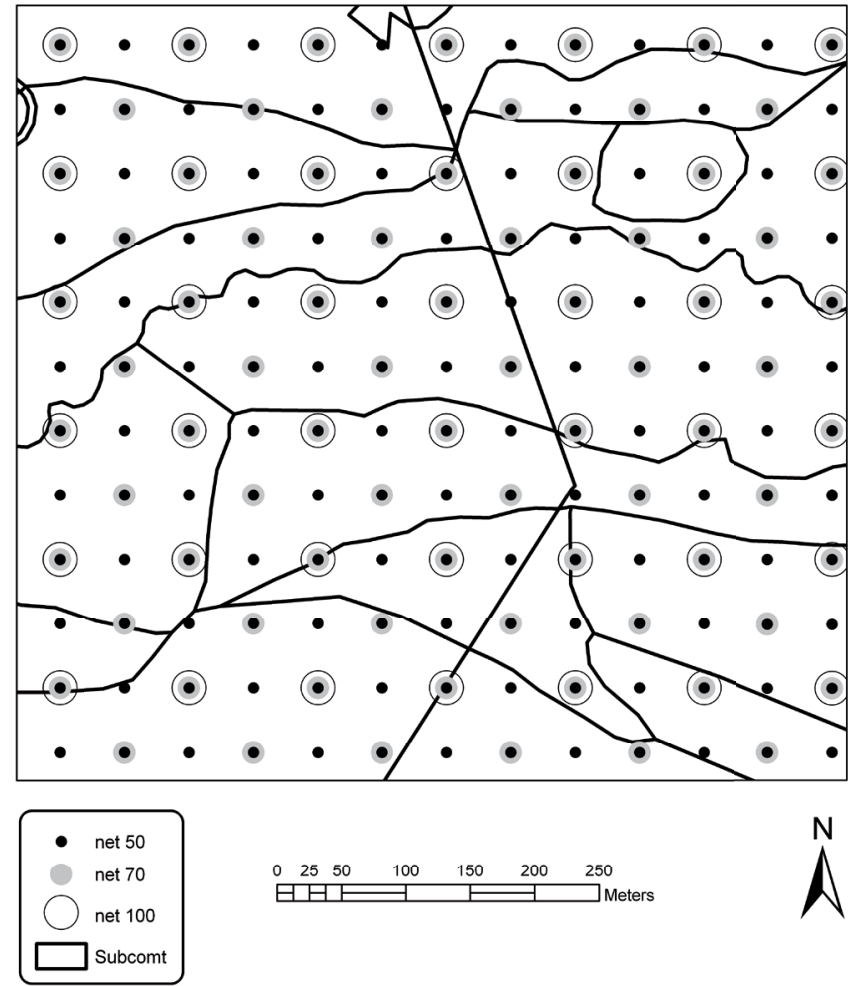

$N$
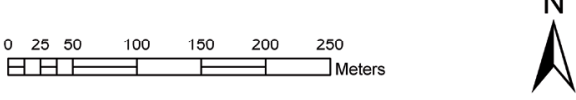
Table 1. Variables collected in the multi-purpose forest state survey with brief descriptions of the most important attributes.

\begin{tabular}{|c|c|c|c|}
\hline Sampling unit & Variable group & Variable & Definition and/or codomain \\
\hline \multirow{6}{*}{ 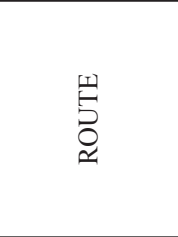 } & & Site-related microhabitats & rockwall, spring, etc. \\
\hline & & Natural disturbance & recent and large disturbances \\
\hline & & Disturbance type & broken tree, fallen stem, fire, biotic agents \\
\hline & & Large trees & outstanding live or dead trees \\
\hline & & Invasive tree species & any form of invasive tree species \\
\hline & & Animal traces and indicator species & bough bird nest, woodpecker trace, N2000 species \\
\hline \multirow{24}{*}{$\begin{array}{l}\mapsto \\
0 \\
-1 \\
a\end{array}$} & \multirow[b]{2}{*}{ General description } & Main category & mature, young, regenerating stand \\
\hline & & Physiognomy in mature stand & $\begin{array}{l}\text { sprout stems, merging canopy and shrub layers, } \\
\text { pasture land use }\end{array}$ \\
\hline & $\begin{array}{l}\text { Features of regenerating } \\
\text { stands }\end{array}$ & $\begin{array}{l}\text { Regeneration cover in regenerating } \\
\text { stand } \\
\text { Description of the regenerating stand } \\
\text { Weed and shrub species in } \\
\text { regenerating stand }\end{array}$ & \\
\hline & \multirow[t]{3}{*}{$\begin{array}{l}\text { Canopy composition and } \\
\text { structure }\end{array}$} & Tree species composition & $\begin{array}{l}\text { percentage value based on visual estimation } \\
\text { record every occurring tree species by estimating } \\
\text { cover in broad categories }(0-5 \%, 6-20 \%, 21-50 \% \text {, } \\
51-100 \%) \text { in diameter classes } \\
(\varnothing: 0-8,9-20,21-35,36-50,>50 \mathrm{~cm}) \text { per species }\end{array}$ \\
\hline & & Bark stripping & fresh damages on at least $5 \%$ of stems \\
\hline & & Anthropogenic stem damage & fresh damages on at least $5 \%$ of stems \\
\hline & \multirow{4}{*}{ Standing deadwood } & $\begin{array}{l}\text { Number of standing dead trees } \\
(>2.5 \mathrm{~m})\end{array}$ & $\begin{array}{l}\text { number of stems in diameter classes (Ø: 9-20, 21- } \\
50,>50 \mathrm{~cm})\end{array}$ \\
\hline & & Decay stage of standing dead tree(s) & fresh, mixed, decayed \\
\hline & & Standing dead trees species & identified species \\
\hline & & Number of snags $(<2.5 \mathrm{~m})$ & $\begin{array}{l}\text { number of stems in diameter classes (Ø: 9-20,21- } \\
50,>50 \mathrm{~cm} \text { ) }\end{array}$ \\
\hline & \multirow[t]{3}{*}{ Lying deadwood } & Quantity of lying deadwood & $\begin{array}{l}\text { visual estimation of FWD }(\varnothing: 0-8 \mathrm{~cm}) \text { and CWD } \\
(Ø: 8-\mathrm{cm}) \text { quantity and diameter distribution in } 9 \\
\text { categories }\end{array}$ \\
\hline & & Decay stage of CWD & fresh, mixed, decayed \\
\hline & & CWD species & identified species \\
\hline & \multirow{5}{*}{ Herbs } & Herb cover & percentage value based on visual estimation \\
\hline & & Dominant herb species & herbs with over $20 \%$ relative cover (max. 3 species) \\
\hline & & Site indicator herbs & moisture and acidity indication (max. 3 species) \\
\hline & & Adventive herbs & \\
\hline & & Herbs indicating disturbance & relative cover (ordinal scale) \\
\hline & \multirow{6}{*}{$\begin{array}{l}\text { Microhabitats and } \\
\text { disturbances }\end{array}$} & Tree-related microhabitats & rootplate, stump, bird hole, Polypores, etc. \\
\hline & & Soil disturbance & severity of soil disturbance (ordinal scale) \\
\hline & & Soil disturbance type & wheel, skidding, game \\
\hline & & Rock cover & rock cover (ordinal scale) \\
\hline & & Debris size & rubble (small, medium, large), bedrock \\
\hline & & Adventive species present & $\begin{array}{l}\text { adventive regeneration and shrub species present } \\
\text { outside the subplot }\end{array}$ \\
\hline \multirow{10}{*}{ 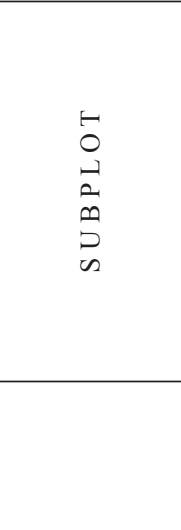 } & \multirow{3}{*}{ Shrubs } & Shrub cover & $\begin{array}{l}\text { percentage value based on visual estimation (ordinal } \\
\text { scale) }\end{array}$ \\
\hline & & Dominant shrub species & $\begin{array}{l}\text { shrubs with over } 20 \% \text { relative cover (max. } 3 \\
\text { species) }\end{array}$ \\
\hline & & Site indicator shrubs & moisture indication \\
\hline & \multirow{4}{*}{ Regeneration } & Cover of high and low regeneration & $\begin{array}{l}\text { percentage value based on visual estimation above } \\
\text { and below } 0.5 \mathrm{~m} \text { (ordinal scale) }\end{array}$ \\
\hline & & Regeneration tree species & dominant and non-dominant species \\
\hline & & Browsing & unbrowsed, slightly, heavily browsed, bonsai-like \\
\hline & & Proportion of sprouts & \\
\hline & \multirow{3}{*}{ Documentation } & GPS coordinates & coordinates of plot center \\
\hline & & Photographs & $\begin{array}{l}\text { photo documentation towards N,W,S,E, upward and } \\
\text { plot center }\end{array}$ \\
\hline & & Comment & comment regarding any variable \\
\hline
\end{tabular}


subplot (radius: $3.09 \mathrm{~m}$ ). Between plots, variables occurring at coarse spatial scales and attributes carrying particular interest even if found only outside the plots are recorded on the route. The route is defined as the visible area from the grid line including the plot of arrival.

The most important variable groups include canopy composition and structure, deadwood, herb species, shrubs, regeneration, microhabitats and game pressure (Table 1). Newly developed methods are described in detail and rationale for the most important variables are given below, while the entire protocol with definitions and explanations is provided in the Appendix.

The main aim of data collection on canopy composition is to describe the cover of every appearing tree species and to detect rare species. Canopy cover of each tree species is estimated in five diameter classes $(0-8 \mathrm{~cm}, 9-20 \mathrm{~cm}, 21-35 \mathrm{~cm}$, $36-50 \mathrm{~cm},>50 \mathrm{~cm}$ ) resulting in complex data on horizontal and vertical structure. Cover is estimated in broad categories (0-5\%, 6-20\%, 21-50\%, 51-100\%).

Deadwood data are currently missing in the National Forestry Database, therefore a simple, but powerful measurement technique has been chosen. Standing dead trees (height $>2.5 \mathrm{~m}$ ) and snags (height $<2.5 \mathrm{~m}$ ) are counted in three diameter classes regardless of their volume. The amount of lying deadwood is visually estimated and compared against a nine-category scale in which choices are represented by images that show typical amounts and diameter distributions of deadwood based on preliminary studies. Categories 1 to 3 stand for cases where increasing amounts of only fine woody debris (FWD, logs with diameter $\leq 8 \mathrm{~cm}$ ) occur. Categories 4 to 6 are used where course woody debris (CWD) is also represented in the plot with $\operatorname{logs} 9-35 \mathrm{~cm}$ in diameter. The last three categories ( 7 to 9 ) describe situations where logs larger than $35 \mathrm{~cm}$ are also present. This scale is more sensitive in the lower part considering the low amount of dead wood in commercial forests.

Data on herbaceous species focus on habitat indication, the presence of adventive and disturbance indicator species. To this end, a confined list of herbs recognisable throughout the growing season has been put together. This approach also enhances data uniformity in case of many field surveyors. Dominant and site indicator shrub species are recorded and data on tree species in the regeneration (dominants and others) are also collected.

Presence of selected tree microhabitats (e.g., low cavity, bark pocket, polypores, for details see Table 1 and Appendix) is collected with the aim of differentiating between microhabitat-poor and -rich zones. Categories have been defined in a way that enables clear distinction between objects and can be recorded quickly. Game pressure is estimated by soil disturbance, browsing of regeneration and bark stripping.

At each sampling plot six photographs are taken for documentation and averaged longitude and latitude coordinates are collected. On average a complete survey of a single sampling plot lasts 20 minutes for a single field surveyor.

A digital data collection system has been developed for the purposes of the forest state survey. Forms are filled in using the ForestDataCollect (FDC) Android application developed by our team. EVOLVEO StrongPhone Q4 is used to run the app, while GPS coordinates are recorded using Garmin GPSMap 64 equipment. The empty forms are downloaded safely for fieldwork in predefined packages containing approx. 30 grid points using the FDC app. There are several data input widgets including table question (Figure 4a) and search list question (Figure $4 \mathrm{~b}$ ) that were not found in the tested available data collection apps. With the table question (Figure 4a), several attributes can be collected for one entity (in our case tree species), and since species lists are long, the search list widget provides easy access to species through favourites and a search field. As an example of other widgets, picture select question has been used to aid visual estimation of lying deadwood (Figure 4c). After completing the data recording, the finished packages are uploaded and integrated into the PostGIS database together with the photographs and GPS coordinates. Processes are semi-automated using Python scripts.

A crucial prerequisite of guaranteeing high quality data is the training of field crew. All crew members had to take part in a series of indoor and outdoor training lessons and had to pass exams. Field training takes place at

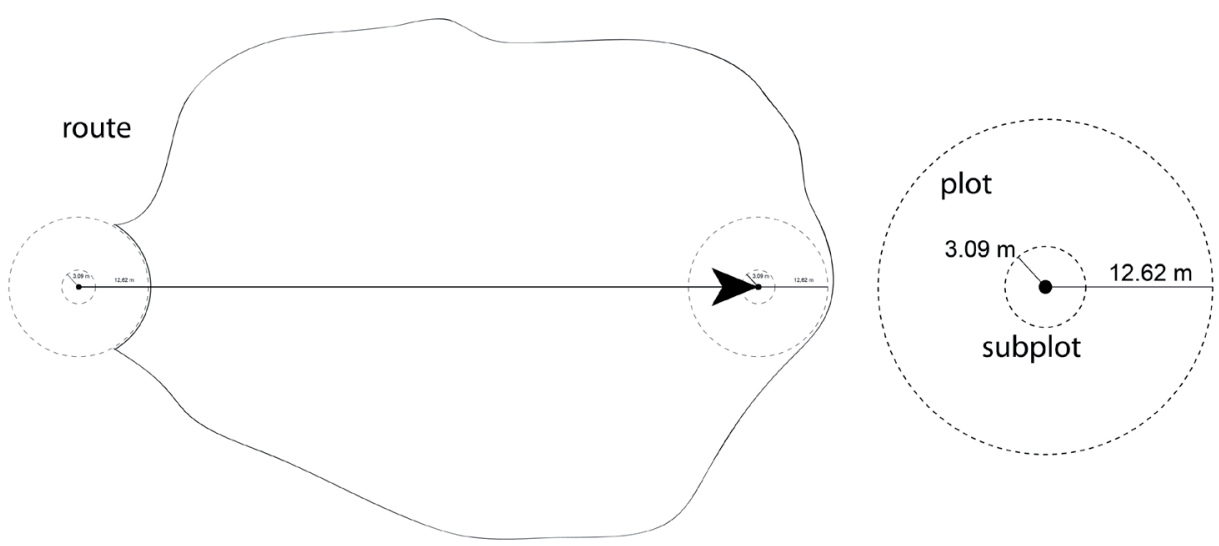

Figure 3. Sampling units used in the multipurpose forest state survey. The extent of the plot and subplot is estimated visually with regular controlling measurements. Most variables are collected in the circular plot, while shrubs and regeneration are measured in the subplot. The route is defined as the area visible when a surveyor walks from one plot to the next. 
the beginning of every field season. Quality assurance is also implemented during field work, data import and data analysis. The smartphone application excludes misspelling of species names and incoherent data through constraints and within-form rules. Only consistent data are imported into the database and a record-based manual quality control ensures credible data. Differences between pairs of surveyors is checked by analysing data that were collected in packages set out in a chequerboard design (Figure 5).

\section{Illustrative example applications}

The whole forest state survey system is designed to enable the collection of large numbers of samples. During the lifetime of the project several tens of thousands of plots have to be sampled. The case studies shown below are based on data collected in roughly 12000 plots during the first field season in 2014.

An important application of the forest state survey is that distribution maps can be drawn for tree species that can serve
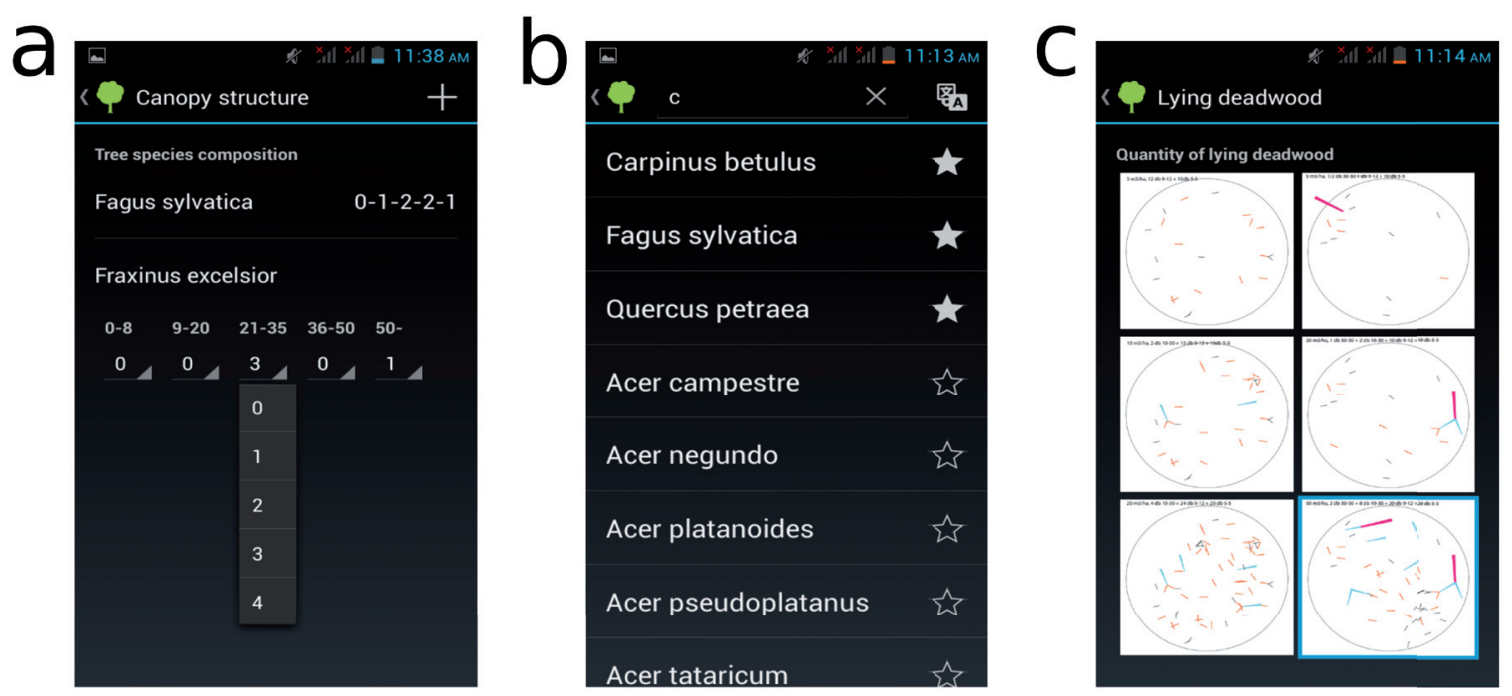

Figure 4. ForestDataCollect android data collection application screenshots. a) Table widget used to collect cover categories in each diameter class and species. b) Search list widget used to select species from long lists aided by dynamic selection of favourites moved to the top of the list and search field that narrows down the list to matching entries. c) Image select widget showing $500 \mathrm{~m}^{2}$ circular plots with varying amount and diameter distribution of lying deadwood. Choice is made in the field by comparing the images against the sampling plot and selecting the most similar scenario.
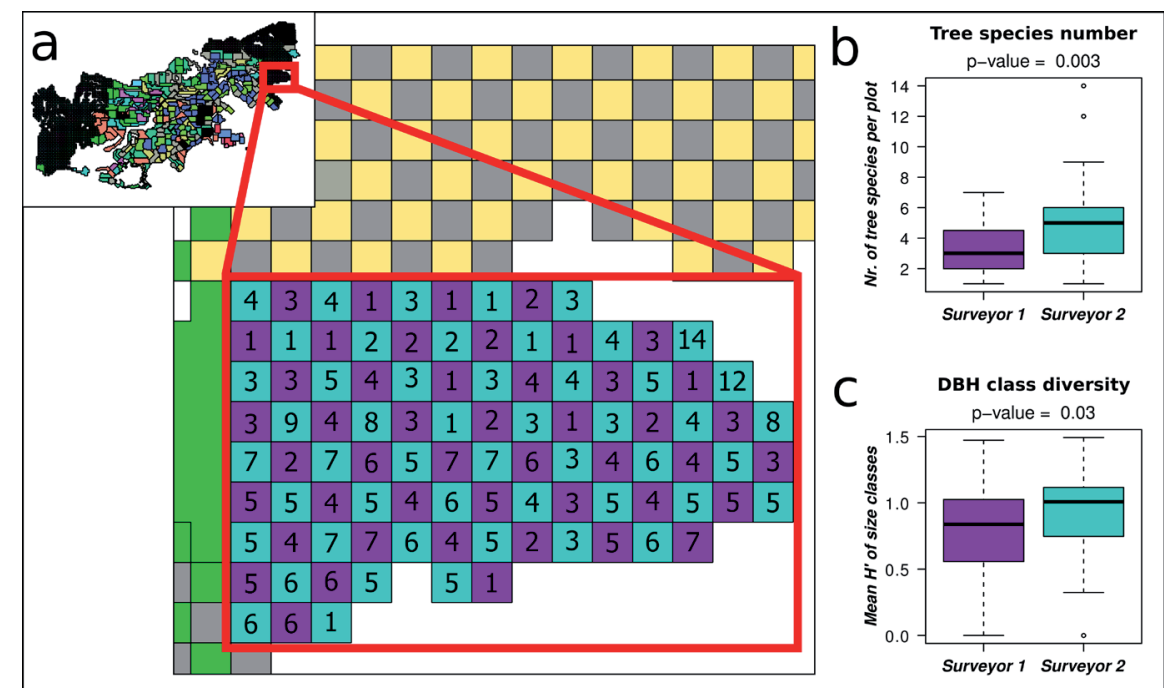

Figure 5. Graphical illustration of data quality assurance based on chequerboard-design and two examples for testing surveyors' data quality. a) One of the chequerboard subsets is shown from Aggtelek Mts. (overview map). Pixels are derived from the $100 \mathrm{~m} \times 100$ $\mathrm{m}$ grid. Points belonging to a given field surveyor are represented by a specific colour. On the map, species number observed by the surveyors are marked within the pixels. b) Comparison of the two surveyors based on tree species number using t-test. c) Comparison of the two surveyors based on diameter class diversity using t-test. 


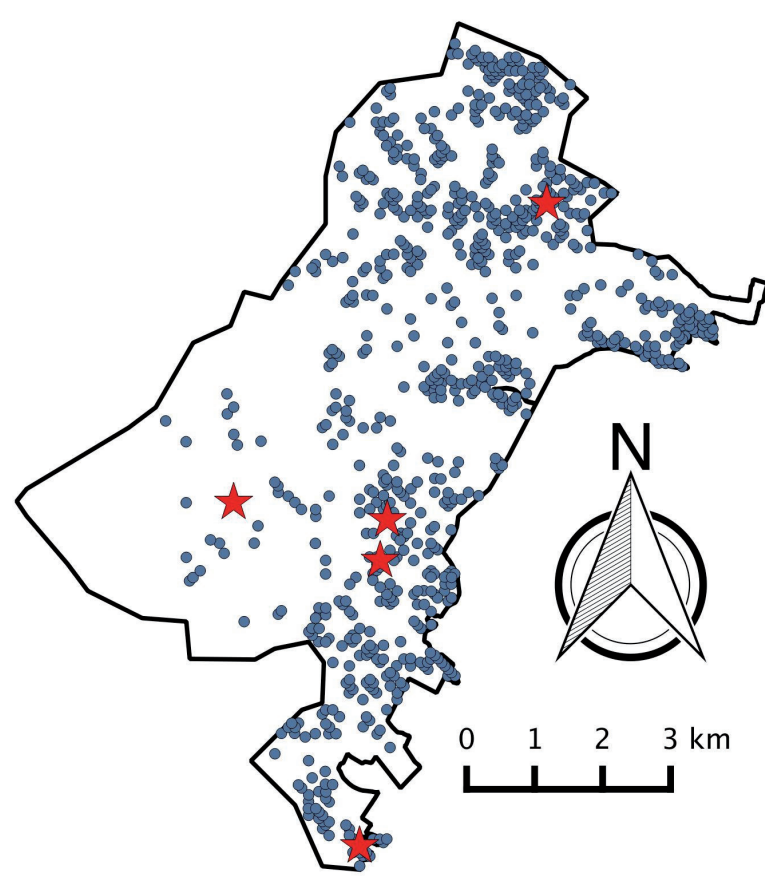

Figure 6. Distribution of Cerasus avium (L.) Moench in the mapped area of the Börzsöny Mts., Northern Hungary. Dots show occurrences of the species in any diameter class, while large $(>50 \mathrm{~cm} \mathrm{DBH})$ trees are indicated by stars. as hosts for specialist species. The location of such rare or economically unimportant species is often unknown, since they are not surveyed. During the first field season of our survey, more than 20000 new records on the occurrence of 36 native tree species were gathered in the 11194 sampling points that contained canopy trees. Compared with data taken from the National Forestry Database, new tree species were recorded in $97 \%$ of the sampled forest subcompartments. Since several specialist birds, bats, insects or fungi colonize their host tree individuals if they are above a certain age or size (translated to diameter at breast height (DBH), e.g., > 50 $\mathrm{cm} \mathrm{DBH})$, tree species distribution maps can be refined by diameter classes (Figure 6). Such maps can be used to specifically search for new occurrences of specialist animal species.

Tree species number varied between 1 and 12 with an average of about 4 species/plot. The diameter distribution of trees within plots seemed rather diverse. All diameter classes appeared in $15 \%$ of the plots, while only $9 \%$ contained just one diameter class. As Figure 7 shows, there is a general positive - though not necessarily significant - relationship between species number and diameter class diversity (DCD, calculated as Shannon-diversity based on relative cover of diameter classes), however relatively high DCD values occurred even if tree species number is low, and vice versa. Using both variables, we can identify forests that have the most diverse canopy (see Figure 7).
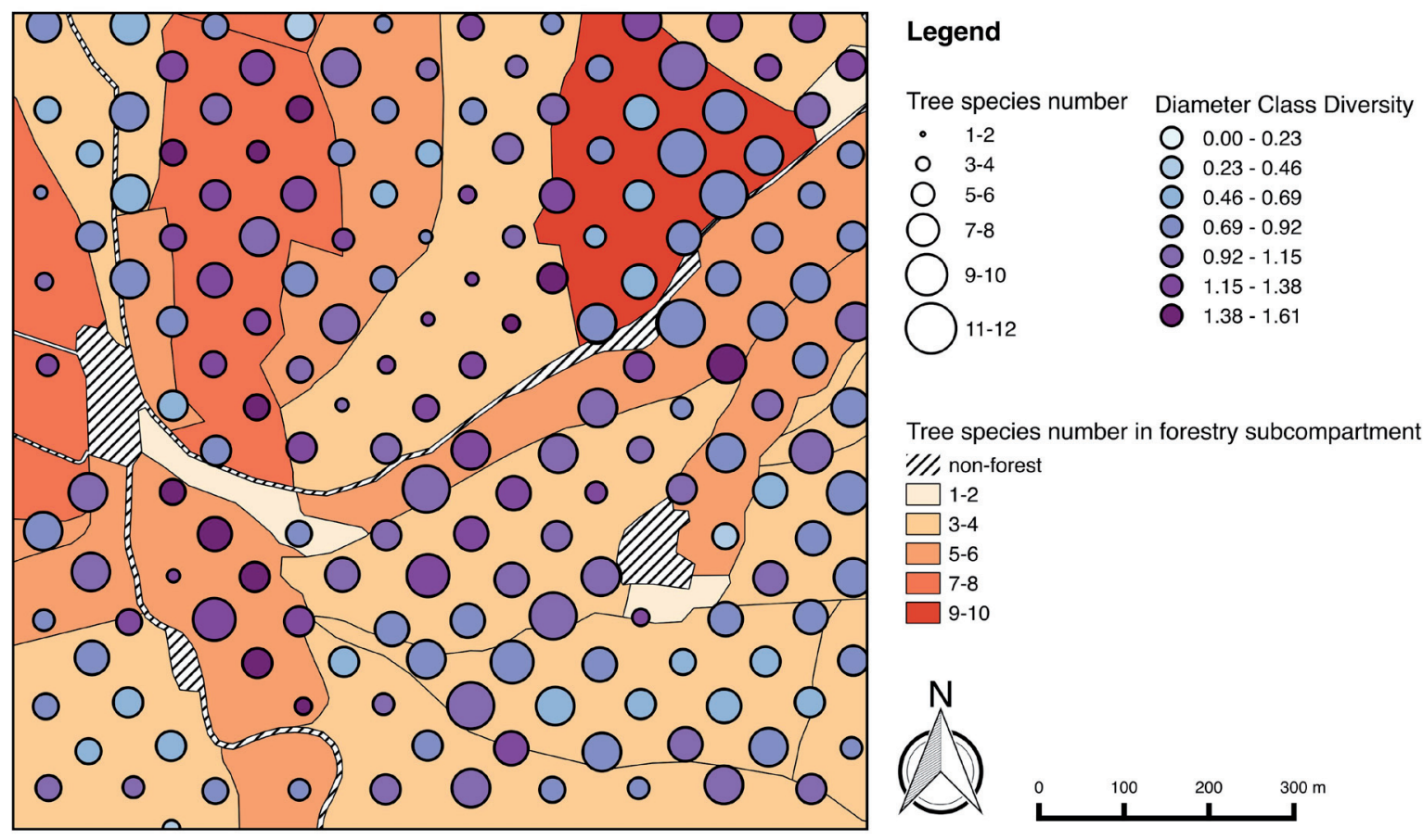

Tree species number in forestry subcompartment I/, non-forest

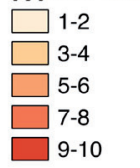

Figure 7. Tree species richness and diameter class diversity. Sizes of circles represent species richness, while their colour represents diameter class diversity. The applied sampling density is $70 \mathrm{~m} \times 70 \mathrm{~m}$. Some "holes" can be seen in the grid: those are either meadows or roads that could not be sampled. Species richness and diameter class diversity (DCD) was calculated for single plots. For DCD, middle cover values were summed in each diameter class and Shannon diversity index was calculated for the classes to account for evenness. The polygons of forest subcompartments are shown displaying species number recorded in the National Forestry Database (NFD). The number of species in the NFD is generally lower for the entire subcompartment than in the multi-purpose forest state assessment. The main reason for that is NFD is interested in economically important tree species and even though all admixing tree species are recorded if they reach $5 \%$ cover, many species remain unrecorded because of the sampling design of NFD. 


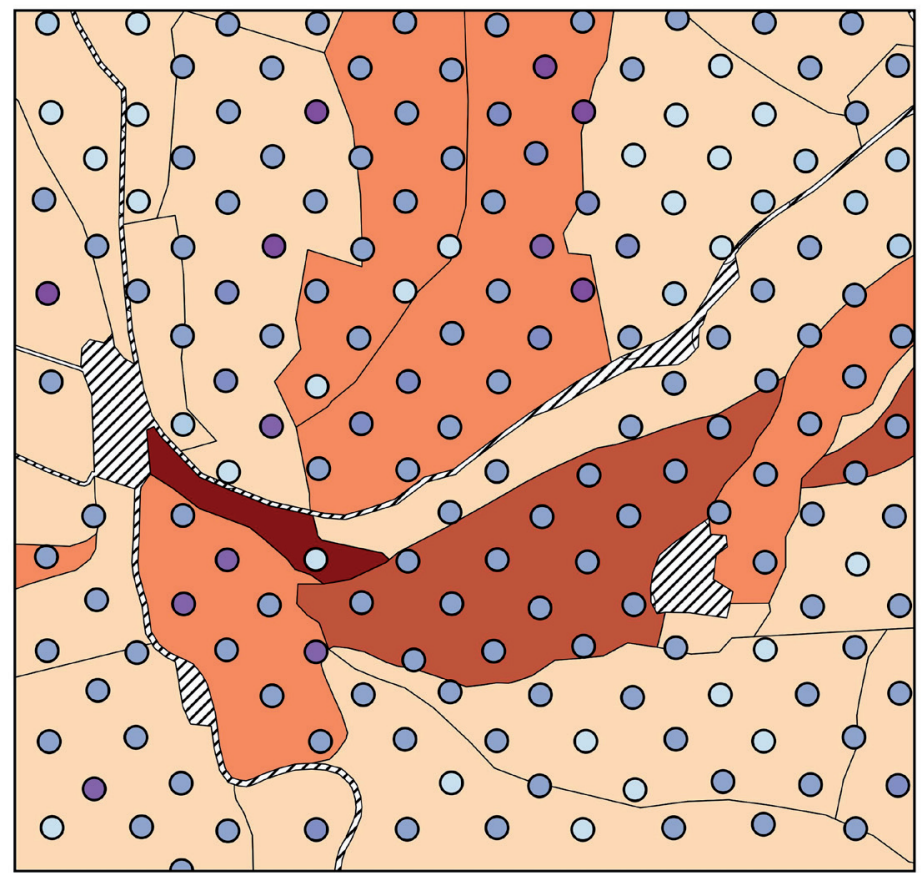

\section{Legend}

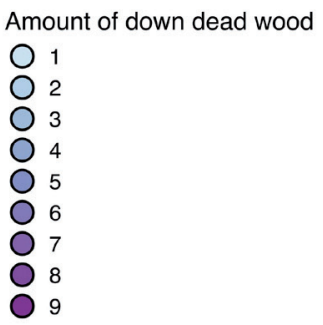

Naturalness of subcompartment Y/, non-forest

$\square$ near-natural

$\square$ semi-natural

$\square$ altered

cultural

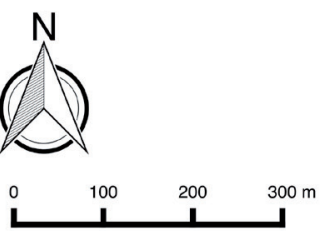

Figure 8. Amount and quality of lying deadwood and forest naturalness. Lying deadwood was estimated using a 9 category scale within sampling plots (see Figure 4). Forest naturalness index is part of the National Forestry Database the unit of which is the forestry subcompartment. The index can take the following values: 1 - natural, 2 - near-natural, 3 - semi-natural, 4 - altered, 5 - cultural, 6 - plantation forests. Only relevant categories are shown in the map legend.

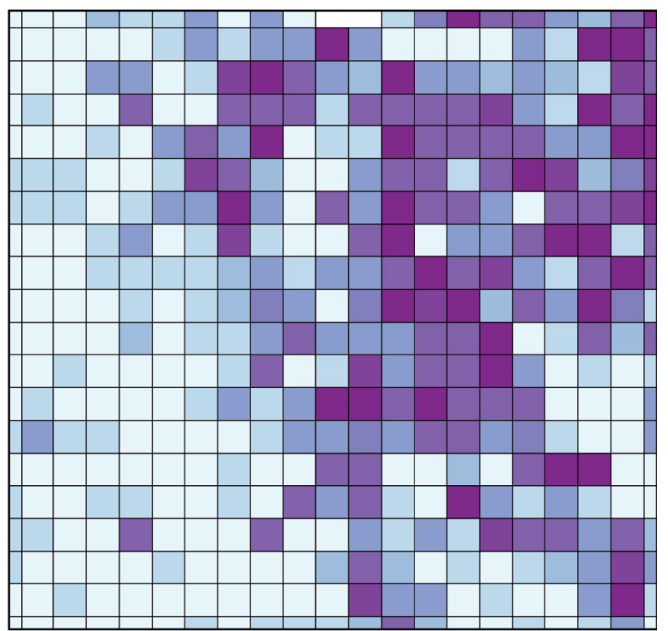

a

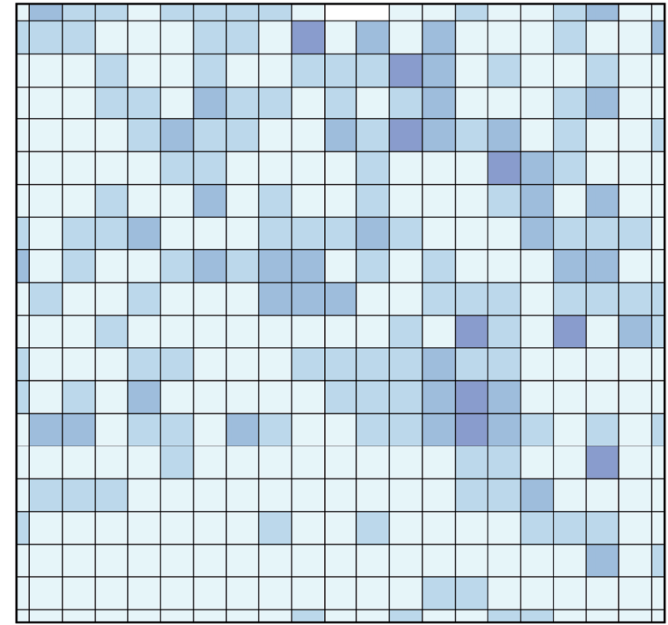

b
Legend

Relative frequencies (\%) of tree related microhabitats $\square-12.5$ $\square 12.5-25$ $\square 25-37.5$ $\square 7.5-50$ $50-62.5$ $62.5-75$
$75-87.5$ $75-87.5$
$87.5-100$

Figure 9. Relative frequencies (\%) of tree related microhabitats. Pixels are 5 ha squares and relative frequency is calculated as the number of presence values over total number of measurement plots within the pixel. a) Rootplates. Rootplates are defined as pit and mound structures following the fall of a tree regardless of size and whether the tree remains there. b) Microhabitats for xylophagous insects. This selection includes high and low cavity, mirror (bark loss) and deadwood on living tree.

Species richness and DCD alone cannot be used to estimate naturalness, as these variables are not sensitive to the presence of alien species in the sampled forests. Almost $8 \%$ of the plots contained adventive species outside plantations. Most of the occurrences were Robinia pseudoacacia L. individuals (633), followed by Quercus rubra L. (88) and Juglans regia L. (80). Data on alien species can be used during man- agement planning (e.g., restriction of thinning) and for habitat restoration (removing alien species).

The amount of lying deadwood in individual plots is shown in an exemplary map in Figure 8 using the forest naturalness categories of forestry subcompartments as applied in the National Forestry Database as background. As it is distinctly visible, our novel methodology provides data on eco- 
logically relevant variables (in this case deadwood) missing from the NFD at a finer spatial scale providing a basis for a more sensitive assessment of forest naturalness than NFD data can supply.

Tree-related microhabitats can serve as indicators of potential occurrence of forest specialist species such as xylophagous insects, but the presence or absence within one plot does not convey enough information on the probability of occurrence. Instead, the ratio of plots that contain a microhabitat type, or a selection of microhabitats within a larger area may provide useful input for the assessment of naturalness and potential biodiversity. Rootplates (Figure 9a) and a selection of microhabitats important for xylophagous insects (Figure $9 b)$ have been chosen for illustration of such clustered maps. The relative frequency of rootplates can also be used as an indicator of the intensity of natural disturbance events (e.g., windfall, ice-break).

\section{Conclusions}

Our aim was to develop a tool that provides reliable and relevant data for supporting strategic planning of both forest management and nature conservation. Our method needs relatively low manpower input per plot, and uses solid estimator methods combined with user-friendly direct database recording. Based on the experience from fieldwork we claim that the methodology shown in this paper meets our prior expectations.

We found that - after necessary training - this forest state survey could be carried out by many field crew of different original background. Also, the chosen technical solutions for data recording and data management proved to be functional and reliable.

We managed to produce relevant (both from conservation and forestry viewpoints) thematic maps based on individual attributes. The versatile use of such maps (examples in Figs. 6-9) could be a much more efficient tool in management planning than traditional polygon-based maps using single or just a few attributes for classification. Attributes can also be freely combined to create specific scales of forest quality and rank plots based on various aspects. This was illustrated by showing the number of tree related microhabitats relevant for xylophagous insects. Similarly, high potential biodiversity of specific organism groups can also be defined using relevant combinations of the recorded variables. Fine-scale data will enable planning activities (e.g., decision on the amount and location of green retention, pinpointing valuable habitat patches) within forestry subcompartments. On the other hand, by aggregating data, landscape scale considerations can be taken into account as well.

In addition to supporting management planning, our results could be applied for monitoring the effects of habitat management, for assessing the conservation status of Natura 2000 habitats, or for supporting habitat suitability assessments.

However, it is not only the quality or theoretical usefulness of these data that determine how extensively they will be utilised. It is equally important that all actors in the respective fields are sufficiently informed and ready to collaborate using a common information platform.

Acknowledgements: The project is supported by a grant from Switzerland through the Swiss Contribution ("Multipurpose assessment serving biodiversity conservation in the Carpathian region of Hungary", registration number SH/4/13). The authors are grateful to Cs. Kozák who developed the android app. We thank L. Kolozs (National Food Chain Safety Office, Forestry Directorate), J. Ruff (Ipoly Erdő LC) and K. Sipos (Danube-Ipoly National Park Directorate) for their advice, critiques and continuous support during the development of the methodology. Last but not least our thanks go to all the field surveyors of our project without whom this methodology could have never been implemented.

\section{References}

Bartha, D., P. Ódor, T. Horváth, G. Tímár, K. Kenderes, T. Standovár, J. Bölöni, F. Szmorad, L. Bodonczi and R. Aszalós. 2006. Relationship of tree stand heterogeneity and forest naturalness. Acta Silv. Lign. Hung. 2: 7-22.

Brambilla, M., M. Gustin and C. Celada. 2011. Defining favourable reference values for bird populations in Italy: setting long-term conservation targets for priority species. Bird Conserv. Int. 21: $107-118$.

Cantarello, E. and A. Newton. 2008. Towards cost-effective indicators to maintain Natura 2000 sites in favourable conservation status. Preliminary results from Cansiglio and New Forest. iForest 1: 75-80.

Chirici, G., R.E. McRoberts, S. Winter, R. Bertini, U.-B. Braendli, I. A. Asensio, A. Bastrup-Birk, J. Rondeux, N. Barsoum and M. Marchetti. 2012. National Forest Inventory Contributions to Forest Biodiversity Monitoring. Forest Sci. 58: 257-268.

Chirici, G., S. Winter and R.E. McRoberts (eds.) 2011. National Forest Inventories: Contributions to Forest Biodiversity Assessments: Contributions to Forest Biodiversity Assessments. Springer, New York.

Christensen, M., K. Hahn, E.P. Mountford, P. Ódor, T. Standovár, D. Rozenbergar, J. Diaci, S. Wijdeven, P. Meyer, S. Winter and T. Vrska. 2005. Dead wood in European beech (Fagus sylvatica) forest reserves. Forest Ecol. Manag. 210: 267-282.

EC 2006. Communication from the Commission to the European Parliament, the Council, the Economic and Social Committee and the Committee of the Regions - on an EU Forest Action Plan. COM(2006) 302.

EC 2013. Communication from the Commission to the European Parliament, the Council, the Economic and Social Committee and the Committee of the Regions - A new EU Forest Strategy: for forests and the forest-based sector. $\operatorname{COM}(2013) 659$.

EEA 2015. State of nature in the EU. Results from reporting under the nature directives 2007-2012. Publications Office of the European Union, Luxembourg.

Evans, D. 2006. The Habitats of the European Union Habitats Directive. Biol. Environ. 106: 167-173.

Fischer, R., O. Granke, G. Chirici, P. Meyer, W. Seidling, S. Stofer, P. Corona, M. Marchetti and D. Travaglini D. 2009. Background, main results and conclusions from a test phase for biodiversity assessments on intensive forest monitoring plots in Europe. iForest 2: 67-74. 
Gouix, N., P. Sebek, L. Valladares, H. Brustel and A. Brin. 2015. Habitat requirements of the violet click beetle (Limoniscus violaceus), an endangered umbrella species of basal hollow trees. Insect Conserv. Diver. 8: 418-427.

Grabherr, G., G. Koch and H. Kirchmeir. 1998. Hemerobie österreichischer Waldökosysteme. Ver öff. Österr. MAB-Programm 17: $1-493$.

Hernando, A., R. Tejera, J. Velázquez and M. Núñez. 2010 Quantitatively defining the conservation status of Natura 2000 forest habitats and improving management options for enhancing biodiversity. Biodivers. Conserv. 19: 2221-2233.

Hochbichler, E., A. O'Sullivan, A. van Hees and K. Vandekerkhove. 2000. WG2 Recommendations for Data Collection in Forest Reserves, with an Emphasis on Regeneration and Stand Structure. In: J. Pärviainen (ed.), COST Action E4 Forest Reserve Research Network. Office for Official Publications of the European Communities, Luxembourg. pp. 135-181.

Kangas, A. and M. Maltamo (eds.) 2006. Forest Inventory: Methodology and Applications. Springer, Dordrecht.

Kent, M. 2012. Vegetation Description and Data Analysis: A Practical Approach. Wiley-Blackwell, Oxford.

Kirby, K.J., C.M. Reid, R.C. Thomas and F.B. Goldsmith. 1998 Preliminary Estimates of Fallen Dead Wood and Standing Dead Trees in Managed and Unmanaged Forests in Britain. J. Appl. Ecol. 35: 148-155.

Kolozs, L. 2009. Forest Monitoring and Observation System (EMMRE) 1988-2008. MGSZH, Budapest.

Kraus, D. and F. Krumm (eds.) 2013. Integrative Approaches as an Opportunity for the Conservation of Forest Biodiversity. European Forest Institute, Freiburg.

Larrieu, L., A. Cabanettes, P. Gonin, T. Lachat, Y. Paillet, S. Winter, C. Bouget and M. Deconchat. 2014. Deadwood and tree microhabitat dynamics in unharvested temperate mountain mixed forests: A life-cycle approach to biodiversity monitoring. Forest Ecol. Manag. 334: 163-173.

Liira, J. and T. Sepp T. 2009. Indicators of structural and habitat natural quality in boreo-nemoral forests along the management gradient. Ann. Bot. Fenn. 46: 308-325.

Lindenmayer, D.B. and J.F. Franklin. 2002. Conserving Forest Biodiversity: A Comprehensive Multiscaled Approach. Island Press, Washington DC.

Louette, G., D. Adriaens, D. Paelinckx and M. Hoffmann. 2015 Implementing the Habitats Directive: How science can support decision making. J. Nat. Conserv. 23: 27-34.

McElhinny, C., P. Gibbons, C. Brack and J. Bauhus. 2005. Forest and woodland stand structural complexity: Its definition and measurement. Forest Ecol. Manag. 218: 1-24.

McRoberts, R.E., S. Winter, G. Chirici and E. LaPoint. 2012 Assessing forest naturalness. Forest Sci. 58: 294-309.

Mehtälä, J. and T. Vuorisalo. 2007. Conservation policy and the EU Habitats Directive: favourable conservation status as a measure of conservation success. Eur. Environ. 17: 363-375.

Molnár, Zs., S. Bartha, T. Seregélyes, E. Illyés, Z. Botta-Dukát, G. Tímár, F. Horváth, A. Révész, A. Kun, J. Bölöni, M. Biró, L. Bodonczi, J.Á. Deák, P. Fogarasi, A. Horváth, I. Isépy, L. Karas, F. Kecskés, Cs. Molnár, A. Ortmann-né Ajkai and Sz. Rév. 2007. A grid-based, satellite-image supported, multi-attributed vegetation mapping method (MÉTA). Folia Geobot. 42: 225-247.
Müller, J., and R. Bütler. 2010. A review of habitat thresholds for dead wood: a baseline for management recommendations in European forests. Eur. J. For. Res. 129: 981-992.

Ódor, P., J. Heilmann-Clausen, M. Christensen, E. Aude, K. van Dort, A. Piltaver, I. Siller, M.T. Veerkamp, R. Walleyn, T. Standovár, A.F.M. van Hees, J. Kosec, N. Matočec, H. Kraigher and T. Grebenc. 2006. Diversity of dead wood inhabiting fungi and bryophytes in semi-natural beech forests in Europe. Biol. Conserv. 131: $58-71$.

Ódor, P. and A.F. van Hees. 2004. Preferences of dead wood inhabiting bryophytes for decay stage, log size and habitat types in Hungarian beech forests. J. Bryol. 26: 79-95.

Paillet, Y., F. Archaux, V. Breton and J. Brun. 2008. A quantitative assessment of the ecological value of sycamore maple habitats in the French Alps. Ann. For. Sci. 65: 713-713.

Parviainen, J., W. Bücking, K. Vandekerkhove, A. Schuck and R. Päivinen. 2000. Strict forest reserves in Europe: efforts to enhance biodiversity and research on forests left for free development in Europe (EU-COST-Action E4). Forestry 73: 107-118.

Tobisch, T. and P. Kottek. 2013. Forestry-related Databases of the Hungarian Forestry Directorate. National Food Chain Safety Office (NFCSO), Budapest

Tomppo, E., J. Heikkinen, H.M. Henttonen, A. Ihalainen, M. Katila, H. Mäkelä, T. Tuomainen and N. Vainikainen. 2011. Designing and Conducting a Forest Inventory - case: 9th National Forest Inventory of Finland. Springer, Dordrecht.

Velázquez, J., R. Tejera, A. Hernando and M.V. Núnez. 2010. Environmental diagnosis: Integrating biodiversity conservation in management of Natura 2000 forest spaces. J. Nature Conserv. 18: 309-317

Winter, S. 2012. Forest naturalness assessment as a component of biodiversity monitoring and conservation management. Forestry 85: 293-304

Winter, S., G. Chirici, R.E. McRoberts and E. Hauk. 2008. Possibilities for harmonizing national forest inventory data for use in forest biodiversity assessments. Forestry 81 : 33-44.

Received May 4, 2016 Revised June 10,2016 Accepted August 19,2016

Open Access. This article is distributed under the terms of the Creative Commons Attribution 4.0 International License (https://creativecommons.org/licenses/by/4.0/), which permits unrestricted use, distribution, and reproduction in any medium, provided the original author and source are credited, you give a link to the Creative Commons License, and indicate if changes were made.

\section{Electronic supplement}

Detailed protocol of the multi-purpose forest state assessment developed in the framework of the project "Multipurpose assessment serving biodiversity conservation in the Carpathian region of Hungary - SH/4/13".

The file may be downloaded from www.akademiai.com. 